\title{
ASSESSING THE FACULTY AND STUDENTS' PERCEPTIONS OF DESIRE2LEARN AND BLACKBOARD
}

\author{
Adnan Chawdhry, California University of PA, chawdhry_a@calu.edu \\ Karen Paullet, merican Public University System, kp1803@online.apus.edu \\ Daniel Benjamin, American Public University System,dbenjamin@apus.edu
}

\begin{abstract}
The student population participating in distance learning education has continued to rise over the past ten years. Both for-profit and non-profit institutions have seen significant increases in the number of courses that are being taught online. Learning Management Systems (LMS) such as Blackboard and Desire 2 Learn (D2L) have made online instructional learning possible. This paper provides a quantitative and comparative assessment of student and faculty perceptions of Blackboard versus Desire 2 Learn. These tools were utilized at a small rural MidAtlantic university during the 2010 and 2011 academic years. A survey was distributed to the undergraduate and graduate student populations to obtain their perceptions of the functionality and use of Blackboard and Desire2Learn, and to assess the difference in their preferences of these two technologies. The students who participated had used both tools at this university. This survey was based upon a study that was conducted at the University of Denver in 2006. The results of the survey were analyzed to better understand the students' perceptions of these technologies and to determine the most commonly used features.
\end{abstract}

Keywords: Blackboard, Desire2Learn, Online Classes, Online Learning, Distance Education, Learning Management System, LMS

\section{INTRODUCTION}

The student population participating in distance learning education has continued to rise over the past ten years. Both for-profit and non-profit institutions have seen significant increases in the number of courses that are being taught online. Learning Management Systems (LMS) such as Blackboard and Desire 2 Learn (D2L) have made online instructional learning possible.

In a continued effort to meet the growing demands for readily accessible education that can be taken anytime and anywhere, colleges and universities are offering more nontraditional courses (online courses). Online learning has the potential to reach constituents that are unable to attend traditional brick and mortar schools. For example, parents who are unable to find a babysitter, soldiers deployed to Iraq and people who do not have access to public transportation can now earn a degree by pursuing online education; this may not have been possible for these constituents in the world of brick and mortar education.

\section{LITERATURE REVIEW}

A study conducted by Chaney, et.al. [2] examined five interrelated assumptions in regard to online learning programs when designing courses and programs in college and university settings. The five assumptions are as follows:

1. Distance learning is not superior to traditional face-to-face instruction

2. Successful distance learning programs are driven by teaching and learning rather than technology

3. Principles of marketing management apply to distance learning program success

4. Successful online/distance courses and programs meet the needs of multiple constituents.

5. A culture of support at all levels of the institution enables success [2]. 


\section{Issues in Information Systems}

Volume 13, Issue 2, pp. 302-310, 2012

Faculty and student perceptions vary with regard to the quality of online education. Literature demonstrates that student learning outcomes are similar in both traditional and online courses. In a study of over 400 universities, Russell [5] and Stewart, et.al [7] did not find any statistical differences between the effectiveness of the traditional and online delivery methods. The most commonly cited factor in development of online degree programs is faculty acceptance [7] [8] [10].

Steward, Bachman, and Johnson [7] conducted a study to measure faculty acceptance of online education, faculty motivation orientation, and intent to teach online. Fifty-eight percent of participants found ease of use to be the top reason to teach online using a learning management system. Faculty also revealed that teaching online could help eliminate scheduling issues for students, reduce problems resulting from commuting, and improved teaching responsibilities [7].

A national study conducted by the Sloan National Commission on Online Learning [4] surveyed faculty members in regard to their perceptions of online learning. A total of 174 regular faculty and 378 part-time faculty completed the survey. Sixty-eight percent of faculty members perceived that learning outcomes in online delivery were inferior to other delivery methods. Eighty percent of faculty members agreed that online education reaches students that could not be served by face-to-face programs. Additionally, $65 \%$ of faculty members believe that training and support are important [4]. A 2010 study conducted by the researchers of online instructional delivery using Blackboard revealed that 31 percent of the students preferred taking classes online. The reasons that students provided for choosing online as their preferred method of taking courses included, time constraints, learning style, and learning effectiveness. Students listed $24 \times 7$ access to course materials and the overall accessibility to the online system as one of the strongest benefits for taking online classes [3].

Of the 1,821 students that completed the survey in the University of Denver's Center for Teaching and Learning's Courseware Faculty Advisory Board (CFAB) study of their student's perceptions of Blackboard, nearly 90 percent attested that Blackboard was an excellent web-based tool. Fewer than two percent reported having a bad experience with Blackboard. The number one reason that students liked Blackboard was the ability to the course materials at any time. They also noted that there was a high level of communication with their instructors. Other benefits included the immediate access to their grades, improved class discussions, and the ability to view assignments. Approximately 82 percent of students preferred courses that utilized Blackboard or other web-based tools as compared to 18 percent that did not [1]. A study of 180 students at Webster University was conducted to determine the pros and cons of online learning perceived by teachers and students. The findings revealed that flexibility of time to work was the most advantageous factor and that lack of face-to-face communication and personal contact with the instructor were the most disadvantageous factors. Other advantages of online learning identified in the study were the ability for a student to work anytime, to work at their own pace and to take more time to think before answering questions [9]. A similar study of student perceptions of online learning revealed that flexibility and the ability to work at one's own pace were the primary benefits. The disadvantages revealed in the study were students' experience with losing work that had been previously completed and the significant latency in screen loads [6].

\section{RESEARCH METHODOLOGY}

The online learning environment enables students all over the world to access higher education; to access classes at their own convenience day or night. The purpose of this study is to compare the faculty and students' perceptions of Blackboard and Desire2Learn. This study explores the following research questions:

RQ1: Is there a significant difference between the perceived benefits and drawbacks among students and faculty?

RQ2: Does the level of satisfaction among students and faculty differ between Blackboard and Desire2Learn?

This study examined faculty and students' perceptions of Blackboard as compared to Desire2Learn, at a small midAtlantic University during the months of February and March 2011. This study utilizes a quantitative methodology 


\section{Issues in Information Systems}

Volume 13, Issue 2, pp. 302-310, 2012

to assess the differences between student and faculty perceptions of both Blackboard and D2L. The population chosen for the student survey was comprised of both undergraduate and graduate students.

Undergraduate students, graduate students, and faculty were surveyed; this assumes that the student population in this study were all 18 years of age or older. The survey was conducted using Survey Monkey, an online survey tool. A total of 246 residential and non-residential students completed the survey. Surveys that were mostly incomplete were excluded from the results of this study. The survey was completed by students who had used both Blackboard and Desire2Learn. The survey was based on a 2006 [1] Blackboard survey conducted at the University of Denver and an earlier study conducted by the researches at a mid-Atlantic University in Pennsylvania in 2010 . The researchers enhanced the survey with additional questions to obtain insights that were not captured in the prior studies. The survey results were analyzed using SPSS, a software tool for statistical analysis. This study used Chisquare with a statistical significance at the .05 margin of error with a $95 \%$ confidence level to determine students' preference of Blackboard or Desire2Learn. Statistical frequencies were used to determine the basis for the students' and faculty use of the two online learning systems. The study was a convenience sample-surveying students and faculty from the School of Arts and Humanities, Business, Science and Match, Engineering, Computer Science, Information Technology, Criminal Justice and Psychology.

The survey instrument consisted of 27 closed-ended questions and one open-ended question. Fourteen of the closedended questions provided an "Other" option, which allowed students to provide responses in addition to predetermined responses listed in each question. The first four questions focused on student demographics; that included gender, age, education, and degree program. Question five, was a contingency question that asked students if they had taken any online distance learning classes. If the students answered yes, they continued to question six which asked if the students had taken online classes using both Blackboard and Desire2Learn. If the students answered yes again, they were to continue with the survey. If the answer was no to either question five or six, the student exited the survey. Based on the students' knowledge and use of both Blackboard and Desire2Learn, questions 7-26 focused on their preferences between the two online management systems. The final question was designed so that students could provide any additional comments or concerns related to Blackboard or Desire2Learn.

\section{RESULTS}

The survey responses were analyzed to assess the faculty and students' perceptions of the benefits and drawbacks and also of their level of satisfaction with Blackboard as compared to Desire2Learn. As illustrated in Figure 1, Faculty made up $13.9 \%$ of the respondents (7.1\% Male and 6.8\% Female) while students made up 86.1\% (33.2\% Male and $52.9 \%$ Female).

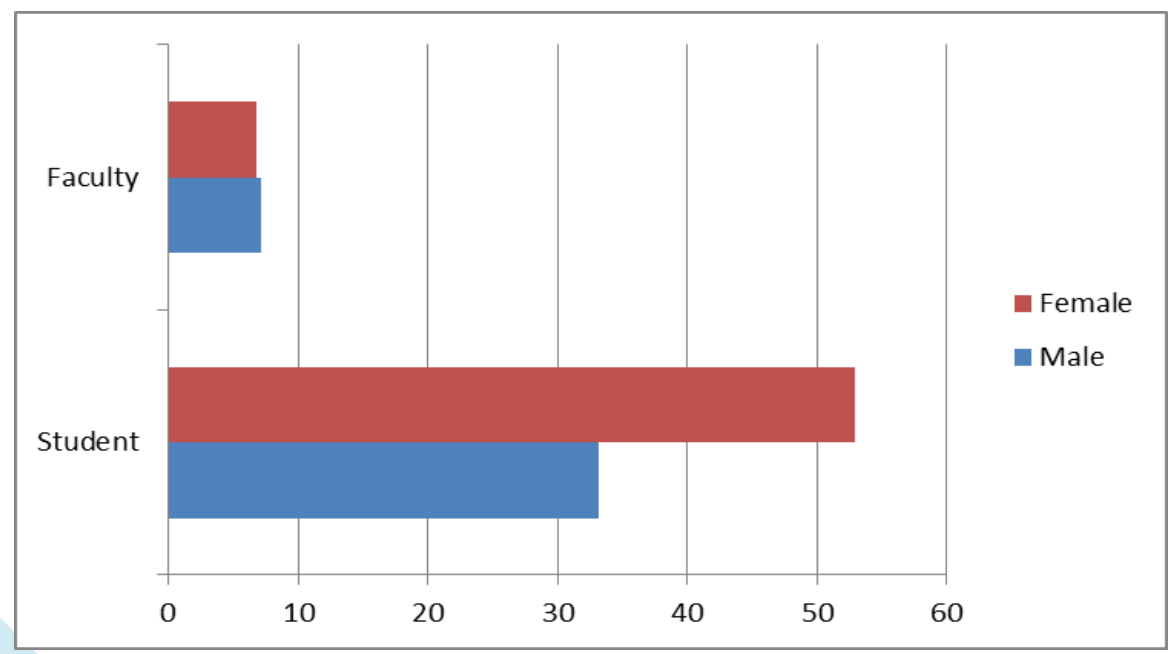

Figure 1. Faculty and Students Broken Down by Gender 


\section{Issues in Information Systems}

Volume 13, Issue 2, pp. 302-310, 2012

The researchers collected data about the faculty and students' perceptions of Blackboard and Desire2Learn. More specifically, they focused on their perceived benefits and drawbacks and the perceived level of satisfaction/dissatisfaction with Blackboard and Desire2Learn. The first comparison evaluated nine benefits of both online systems. For each benefit, the researchers determined the response rate, chi-square value, and its statistical significance. Based upon the requirement of having a statistical significance of less than 5\% (or .05), it was determined that only "Checking Grades" was significant for Blackboard between faculty and students. However, five benefits were found to be statically significant for Desire2Learn between faculty and Students. These five included: (1) Ease of Access to Course Material, (2) Promote Group Discussion, (3) Easy to Use Interface, (4) Checking Grades, and (5) Accessibility. Further details of these results are displayed in Table 1 and Table 2 below.

Table 1. Benefits of Blackboard

\begin{tabular}{|l|r|r|r|r|r|r|}
\hline Benefit & Student & Faculty & Total & df & $\begin{array}{l}\text { Chi- } \\
\text { Value }\end{array}$ & Statistical \\
\hline Ease of access to course materials & 111 & 13 & 124 & 1 & 2.232 & 0.135 \\
\hline Promote group discussion & 61 & 7 & 68 & 1 & 1.011 & 0.315 \\
\hline Enhance Team cohesiveness & 22 & 3 & 25 & 1 & 0.09 & 0.764 \\
\hline $\begin{array}{l}\text { Solicit Feedback from peers and the } \\
\text { instructor }\end{array}$ & 35 & 4 & 39 & 1 & 0.522 & 0.47 \\
\hline Easy to use interface & 77 & 7 & 84 & 1 & 3.159 & 0.076 \\
\hline Checking grades & 130 & 14 & 144 & 1 & 4.383 & 0.036 \\
\hline Quality of assessments & 42 & 3 & 45 & 1 & 2.378 & 0.123 \\
\hline Accessibility & 74 & 8 & 82 & 1 & 1.71 & 0.191 \\
\hline Collaborative group projects & 20 & 3 & 23 & 1 & 0.018 & 0.892 \\
\hline
\end{tabular}

Table 2. Benefits of Desire2Learn

\begin{tabular}{|l|r|r|r|r|r|r|}
\hline Benefit & Student & Faculty & \multicolumn{1}{l|}{ Total } & df & $\begin{array}{l}\text { Chi- } \\
\text { Value }\end{array}$ & Statistical \\
\hline Ease of access to course materials & 120 & 7 & 127 & 1 & 13.637 & 0 \\
\hline Promote group discussion & 67 & 2 & 69 & 1 & 9.293 & 0.002 \\
\hline Enhance Team cohesiveness & 36 & 2 & 38 & 1 & 2.772 & 0.096 \\
\hline $\begin{array}{l}\text { Solicit Feedback from peers and the } \\
\text { instructor }\end{array}$ & 58 & 6 & 64 & 1 & 1.457 & 0.227 \\
\hline Easy to use interface & 83 & 3 & 86 & 1 & 11.266 & 0.001 \\
\hline Checking grades & 130 & 8 & 138 & 1 & 14.865 & 0 \\
\hline Quality of assessments & 43 & 3 & 46 & 1 & 2.539 & 0.111 \\
\hline Accessibility & 81 & 5 & 86 & 1 & 6.827 & 0.009 \\
\hline Collaborative group projects & 18 & 2 & 20 & 1 & 0.284 & 0.594 \\
\hline
\end{tabular}

Other perceived benefits mentioned by the faculty and students included:

- Blackboard

○ Discussion Boards do not freeze after hitting spell check. 


\section{Issues in Information Systems}

Volume 13, Issue 2, pp. 302-310, 2012

- Desire2Learn

- The navigation is much more adapted to an online course.

○ Instructors can check for plagiarism

The questionnaire also asked questions related to the perceived drawbacks of both systems. This included five predefined responses along with one open-ended question for additional feedback. The results of these questions for Blackboard are presented in Table 3 and that for Desire2Learn are presented in Table 4. Based upon these results, it was determined that a statistical significance between the faculty and students' responses exists for both the first three drawbacks in both systems and for the one additional drawback in Desire2Learn.

Table 3. Drawbacks of Blackboard

\begin{tabular}{|l|r|r|r|r|r|r|}
\hline Drawbacks & Student & Faculty & \multicolumn{1}{|l|}{ Total } & df & $\begin{array}{l}\text { Chi- } \\
\text { Value }\end{array}$ & Statistical \\
\hline $\begin{array}{l}\text { Professors don't know how to use it } \\
\text { effectively }\end{array}$ & 66 & 2 & 68 & 1 & 9.046 & 0.003 \\
\hline $\begin{array}{l}\text { Inconsistent use of Blackboard by } \\
\text { instructors }\end{array}$ & 96 & 3 & 99 & 1 & 15.107 & 0 \\
\hline Not used to its potential & 81 & 4 & 85 & 1 & 8.658 & 0.003 \\
\hline Problems with technology / access issues & 50 & 4 & 54 & 1 & 2.395 & 0.122 \\
\hline Have to print everything yourself & 33 & 2 & 35 & 1 & 2.268 & 0.132 \\
\hline
\end{tabular}

Table 4. Drawbacks of Desire2Learn

\begin{tabular}{|l|r|r|r|r|r|r|}
\hline Drawbacks & Student & Faculty & \multicolumn{1}{l|}{ Total } & df & $\begin{array}{l}\text { Chi- } \\
\text { Value }\end{array}$ & Statistical \\
\hline $\begin{array}{l}\text { Professors don't know how to use it } \\
\text { effectively }\end{array}$ & 100 & 7 & 107 & 1 & 7.875 & 0.005 \\
\hline $\begin{array}{l}\text { Inconsistent use of Desire2Learn by } \\
\text { instructors }\end{array}$ & 65 & 2 & 67 & 1 & 8.802 & 0.003 \\
\hline Not used to its potential & 79 & 6 & 85 & 1 & 4.824 & 0.028 \\
\hline Problems with technology / access issues & 53 & 9 & 62 & 1 & 0.018 & 0.892 \\
\hline Have to print everything yourself & 34 & 1 & 35 & 1 & 4.106 & 0.043 \\
\hline
\end{tabular}

Other drawbacks mentioned by Students and faculty included:

- Blackboard

○ Having to check every day if something is posted.

- Missing face-to-face communication

- Unorganized and confusing navigation

- Some professors never touch it.

- Quality of material isn't there.

- Desire2Learn

- Issues printing material.

- Discussion Board freezes when using spell check.

- System goes down frequently.

- Not receiving emails from professors.

- Not permitted to copy and paste in the dropbox.

- Difficult downloading/uploading grades to Excel

- News doesn't send emails like Blackboard 


\section{Issues in Information Systems}

Volume 13, Issue 2, pp. 302-310, 2012

- Needs better mobile capability.

Lastly, faculty and students answered a number of questions to determine their perceived level of satisfaction with Blackboard and Desire2Learn as a technology for online instruction. These questions were further refined to include 10 predefined satisfaction and dissatisfaction responses along with an open-ended selection for the faculty and students to provide additional input. Tables 5 and 6 illustrate the participants' responses about their satisfaction with Blackboard and Desire2Learn. The majority of faculty and students were satisfied with Blackboard while only the majority of students were satisfied with Desire2Learn and majority of faculty were not. If the respondents answered affirmatively, they were asked to identify the reasons for their satisfaction and if they responded negatively, they were asked to identify the reasons for their dissatisfaction. These results are presented in Tables 710 , which also illustrate their associated chi-square value and the significance value. Only significance values of less than $5 \%$ (.05) were considered statistically significant.

Table 5. Satisfaction with Blackboard

\begin{tabular}{|l|r|r|r|}
\hline & Students & Faculty & Total \\
\hline Yes & 157 & 15 & 172 \\
\hline No & 24 & 4 & 28 \\
\hline Total & 181 & 19 & 200 \\
\hline
\end{tabular}

Table 6. Satisfaction with Desire2learn

\begin{tabular}{|l|r|r|r|}
\hline & Students & Faculty & Total \\
\hline Yes & 144 & 8 & 152 \\
\hline No & 37 & 11 & 48 \\
\hline Total & 181 & 19 & 200 \\
\hline
\end{tabular}

Table 7. Satisfaction Reasons with Blackboard

\begin{tabular}{|l|r|r|r|r|r|r|}
\hline Satisfaction & Student & Faculty & Total & df & $\begin{array}{l}\text { Chi- } \\
\text { Value }\end{array}$ & Statistical \\
\hline $24 / 7$ access & 107 & 8 & 115 & 1 & 7.9 & 0.005 \\
\hline improves communication w/ instructor & 51 & 9 & 60 & 1 & 0.065 & 0.799 \\
\hline improves communication with students & 62 & 6 & 68 & 1 & 1.976 & 0.16 \\
\hline facilitates learning & 90 & 8 & 98 & 1 & 4.202 & 0.04 \\
\hline $\begin{array}{l}\text { facilitates collaboration on group } \\
\text { projects }\end{array}$ & 34 & 4 & 38 & 1 & 0.436 & 0.509 \\
\hline helps me learn how to use technology & 43 & 6 & 49 & 1 & 0.149 & 0.699 \\
\hline intuitive & 30 & 6 & 36 & 1 & 0.246 & 0.62 \\
\hline ease of use & 113 & 11 & 124 & 1 & 4.761 & 0.029 \\
\hline small learning curve & 29 & 5 & 34 & 1 & 0.017 & 0.897 \\
\hline Interoperability & 10 & 4 & 14 & 1 & 2.603 & 0.107 \\
\hline
\end{tabular}


Table 8. Satisfaction Reasons with Desire2Learn

\begin{tabular}{|l|r|r|r|r|r|r|}
\hline Satisfaction & Student & Faculty & Total & df & $\begin{array}{l}\text { Chi- } \\
\text { Value }\end{array}$ & Statistical \\
\hline $24 / 7$ access & 122 & 6 & 128 & 1 & 16.653 & 0 \\
\hline improves communication w/ instructor & 67 & 6 & 73 & 1 & 2.71 & 0.1 \\
\hline improves communication with students & 68 & 3 & 71 & 1 & 7.48 & 0.006 \\
\hline facilitates learning & 78 & 3 & 81 & 1 & 9.932 & 0.002 \\
\hline $\begin{array}{l}\text { facilitates collaboration on group } \\
\text { projects }\end{array}$ & 40 & 2 & 42 & 1 & 3.482 & 0.062 \\
\hline helps me learn how to use technology & 51 & 2 & 53 & 1 & 5.64 & 0.018 \\
\hline intuitive & 39 & 1 & 40 & 1 & 5.1 & 0.024 \\
\hline ease of use & 115 & 4 & 119 & 1 & 19.123 & 0 \\
\hline small learning curve & 26 & 0 & 26 & 1 & 4.65 & 0.031 \\
\hline Interoperability & 9 & 1 & 10 & 1 & 0.137 & 0.711 \\
\hline
\end{tabular}

Table 9. Dissatisfaction Reasons with Blackboard

\begin{tabular}{|l|r|r|r|r|r|r|}
\hline Not Satisfied & Student & Faculty & \multicolumn{1}{l|}{ Total } & \multicolumn{1}{l|}{ df } & $\begin{array}{l}\text { Chi- } \\
\text { Value }\end{array}$ & Statistical \\
\hline Can't find what I am looking for & 0 & 0 & 0 & 1 & 0 & 0 \\
\hline Doesn't work properly & 6 & 1 & 7 & 1 & 0.001 & 0.982 \\
\hline rarely kept up to date & 9 & 0 & 9 & 1 & 1.511 & 0.219 \\
\hline I can't learn properly online & 6 & 0 & 6 & 1 & 0.997 & 0.318 \\
\hline I don't like to spend time online & 0 & 0 & 0 & 1 & 0 & 0 \\
\hline It is unorganized and confusing & 12 & 2 & 14 & 1 & 0.001 & 0.974 \\
\hline large learning curve & 3 & 1 & 4 & 1 & 0.409 & 0.522 \\
\hline Poorly designed interface & 9 & 2 & 11 & 1 & 0.167 & 0.682 \\
\hline not intuitive & 4 & 1 & 5 & 1 & 0.153 & 0.696 \\
\hline Hard to navigate & 8 & 1 & 9 & 1 & 0.064 & 0.801 \\
\hline
\end{tabular}

Other input provided on reasons for satisfaction and dissatisfaction of both technologies include:

- Blackboard

- Dissatisfaction

- Most professors are uneducated on how to use the tool

- Ability to open more than one thing at a time.

- Desire2Learn

○ Satisfaction

- Immediate grade feedback

- More options

- Layout is better

- There isn't too much difference from Blackboard allowing an easy transition.

- Some instructors aren't educated on how to use it properly. 


\section{Issues in Information Systems}

Volume 13, Issue 2, pp. 302-310, 2012

- Discussions are difficult

- Difficulty in grading

- Survey's don't work properly

- Issues with taking quizzes.

- Extra mouse clicks needed to navigate.

Table 10. Dissatisfaction Reasons with Desire2Learn

\begin{tabular}{|l|r|r|r|r|r|r|}
\hline Not Satisfied & Student & Faculty & \multicolumn{1}{l|}{ Total } & df & $\begin{array}{l}\text { Chi- } \\
\text { Value }\end{array}$ & Statistical \\
\hline Can't find what I am looking for & 11 & 3 & 14 & 1 & 0.678 & 0.41 \\
\hline Doesn't work properly & 15 & 5 & 20 & 1 & 2.168 & 0.141 \\
\hline rarely kept up to date & 14 & 0 & 14 & 1 & 2.394 & 0.122 \\
\hline I can't learn properly online & 4 & 0 & 4 & 1 & 0.66 & 0.417 \\
\hline I don't like to spend time online & 1 & 0 & 1 & 1 & 0.163 & 0.686 \\
\hline It is unorganized and confusing & 29 & 8 & 37 & 1 & 2.06 & 0.151 \\
\hline large learning curve & 8 & 4 & 12 & 1 & 3.897 & 0.048 \\
\hline Poorly designed interface & 28 & 6 & 34 & 1 & 0.43 & 0.512 \\
\hline not intuitive & 6 & 5 & 11 & 1 & 9.417 & 0.002 \\
\hline Hard to navigate & 23 & 6 & 29 & 1 & 1.206 & 0.272 \\
\hline
\end{tabular}

\section{DISCUSSION}

The first research question was designed to identify the faculty and students' perceived benefits of the two systems to determine if any of the responses were statistically significant. Based upon the results, it seems that Desire2Learn had more responses that were significant between faculty and students for both the benefits and drawbacks. Additionally, it seems that the top two responses by both faculty and students for benefits of both systems were the (1) Ease of Use and (2) Checking Grades.

With both Blackboard and Desire2Learn, students identified that the drawbacks were mostly related to the instructors and their use of the tools. On the other hand, faculty indicated that their drawbacks were more closely aligned with technology/access issues. It is also important to note that faculty listed a larger number of benefits for Blackboard and a larger number of responses of Drawbacks for Desire2Learn. Additionally, students responded more favorably towards Desire2Learn for benefits and roughly equally for Desire2Learn and Blackboard when it comes to the drawbacks.

The second research focused on the perceived level of satisfaction for both tools by faculty and students and attempted to illustrate any difference between the two groups. Based upon the data from the questionnaire, it seemed the majority of students were satisfied with Blackboard and Desire2Learn, however, the total "Yes" response were slightly higher for Blackboard. Faculty felt differently and responded that they were satisfied with Blackboard but the majority was not satisfied with Desire2Learn.

After reviewing the results of satisfaction, it is important to understand the top choices by both faculty and students. For faculty, $24 \times 7$ access and ease of use were the top reasons for their satisfaction with Blackboard. Students also identified these as the top reasons for satisfaction. While these two responses were top choices for student satisfaction with Desire2Learn, faculty felt their top two choices were the $24 \times 7$ access and the improved communication with the instructor. Both faculty and students felt their top reasons of dissatisfaction dealt with the 


\section{Issues in Information Systems}

Volume 13, Issue 2, pp. 302-310, 2012

organization, interface, and navigation. However, an interesting trend was while these choices were the same for faculty and students for both technologies, the actual response were higher on Dissatisfaction reasons for Desire2learn as compared to Blackboard.

\section{CONCLUSION}

For any technology to be effective, it is important that the users be properly trained on using the application effectively in order to leverage the product features. The faculty and students' perceptions indicate that as faculty were not trained properly on Desire2Learn and that leads to their frustration and dissatisfaction with the application. After years of working with Blackboard, they developed a sense of comfort; unfortunately, this comfort was shortlived since they moved to a new online learning tool. Although there seems to be minimal opposition and dissatisfaction with Desiire2Learn, students seem welcoming of the technology and tend to share the same concerns about both applications which stem from an ineffective or non-existent course shell. Ideally, if universities were more involved in the creation of "Standard Shells" and provided additional training on the use of their online learning tools, they are likely to see a higher level of satisfaction on the part of their faculty and students; and the tool which would help create a more effective learning environment.

\section{REFERENCES}

1. The Center. (2006). Blackboard students survey report Winter 2006. The Center for Teaching and Learning at DU Faculty Advisory Board. Retrieved on April 15, 2011 fromctl.du.edu/support/blackboard/BbStudentReportWinter06.pdf

2. Chaney, D., Chaney, E., \& Eddy, J. (2010). The context of distance learning programs in higher education. Five enabling assumptions. Online Journal of Distance Learning Administration, Vol. XIII, No. IV.

3. Chawdhry, A., Paullet, K., \& Benjamin, D. (2011). Assessing Blackboard: Improving online instructional delivery. Information Systems Educators Conference, EDSIG, 2011.

4. NASCULGC (21, April 2009). National survey of faculty perceptions regarding online learning.

5. Russel, G. (2005). The distance question in online education. Innovate, Vol. 1, Issue 4. Retrieved from: http://innovateonline.info/pdf/vol_issue4/thedistance_question_in_onine_education.pdf

6. Smart, K.L., and Cappel, J.J. (2006) Students' perceptions of online learning: a comparative study. Journal of Information Technology Education. Vol. 5.

7. Stewart, C., Bachman, C., \& Johnson, R. (3 September 2010). Predictions of faculty acceptance of online education. Merlot Journal of Online Learning and Teaching. Vol. 6, No.3.

8. Stith, B. (2000). Web-enhanced lecture course scores big with students and faculty members. Business Week. Retrieved from http://www.businessweek.com/magazine/content/01_49/b3760073.htm

9. Tamashiro, R. (2001). Pros and cons of online learning: conflicting perceptions among teacher and education standards.

10. Ulmer, L.W., Watson, L.W., \& Derby. D. (2007). Perceptions of higher education faculty members on the value of distance education. The Quarterly Review of Distance Education, 8, 59-70. 